transarterial and transvenous approaches". Int J Clin Exp Med, 9 (10), 19399-19407.

7. Gao B.-L., Wang Z.-L., Li T.-X., et al. (2018) "Recurrence risk factors in detachable balloon embolization of traumatic direct carotid cavernous fistulas in 188 patients". Journal of neurointerventional surgery, 10 (7), 704-707.
8. Han M.H. (2003) "Endovascular Treatment in Direct Carotid Cavernous Fistula". Interventional Neuroradiology, 9 (2_suppl), 55-62.

9. Korkmazer B., Kocak B., Tureci E., et al. (2013) "Endovascular treatment of carotid cavernous sinus fistula: a systematic review". World journal of radiology, 5 (4), 143.

\title{
NHÂN 3 TRƯỜNG HỢP ÁP XE NÃO DO VIÊM XOANG: CHẨN ĐOÁN VÀ ĐIỀU TRI TẠI BỆNH VIỆN CHỢ RẪY
}

\section{TÓM TẮT}

Qua 3 trường hợp báo cáo, cho chúng ta thây hầu hết triêu chứng của viêm xoang biến chứng áp xe não bao gồm các triệu chứng sau: hội chứng tăng áp lực nội sọ (đau đầu, nôn ói, thay đổi tri giác). Bên canh đó, là triệu chứng về mắt (giảm thị lực/ mù mắt, hạn chế vân nhãn,...). Triêu chứng viêm mũi xoang man thường không râm rộ. 3 trường trường hợp đều được hổ trơ CT scan/ MRI giúp chẩn đoán xác định. Đước điêu trị kết hợp nội khoa, bệnh lý kèm theo và phẫu thuât dẫn lưu ô áp xe, cùng với lây hết bênh tích vùng mũi xoang bị viêm. 3 trường hợp đều điểu trị kéo dài khoảng 4 tuần với kháng sinh qua màng não và đều xuất viện ổn định. Và cho thấy đường lan truyền gây áp xe não từ xoang có thể lan truyền trực tiếp hoặc gián tiếp qua đường máu.

Tư khóa: viêm xoang biến chứng, áp xe não do viêm xoang, áp xe não

\section{SUMMARY \\ DIAGNOSIS AND TREATMENT OF THREE CASES OF SINOGENIC BRAIN ABCESS AT CHO RAY HOSPITAL}

Three cases show the most common symtoms of sinogenic brain abcess including high intracranial pressure syndrome (headache, vomiting, mental disorder). In addition, there arc abnormal symtoms about eyes (loss vision, blindness, limited movement of eyes). The symptoms of chronic rhinosinusitis arc usually not aggressive. These cases took CT scan/ MRI to identify diagnosis clearly. They were cured combined antibiotic therapy and abscess drainage from brain by transnasal endoscopic sinus surgery or craniotomy. All of them improved good their health. And they can went out from the hospital. Sinogenic causes maybe invade directly into brain tissue by anterior skull base or indirectly into bloodstream and move until brain. Keywords: sinogenic brain abcess, sinusitis with brain abcess complaintions, brain abcess.

*Bệnh viện Chỡ Rẫy

Chiu trách nhiểm chính: Ngô Văn Công

Email: congtmh@gmail.com

Ngày nhận bài: 23.8.2021

Ngày phản biên khoa họ: 22.10.2021

Ngày duyệt bài: 1.11.2021
Ngô Văn Công*

\section{GIỚI THIẸU}

Trong kỷ nguyên kháng sinh, biến chứng nôi so do viêm xoang trở nên rất hiếm [1][2]. Tỷ lệ biến chứng 3,7\% được báo cáo ở các bệnh nhân nhập viện với viêm xoang cấp tính hoặc mạn tính [3]. Khả năng viêm xoang đe dọ tính mạng liên quan biến chứng nội sọ bao gồm tụ mủ dưới màng cứng, áp xe ngoài màng cứng hoặc áp xe trong não, viêm màng não, và thuyên tắc xoang tĩnh mạch. Hầu hết các biến chứng liên quan đến xoang trán và sau đó theo thứ tự với xoang sàng, xoang bướm và xoang hàm [4].

Người trưởng thành và trẻ em lớn hơn 6 tuổi được yếu tố nguy cơ cao biến chứng từ nhiễm trùng đường hô hấp trên. Thứ nhất, mạch máu của hệ thống tủy xương là ở giai đoạn cao điểm, và thứ 2 có liên quan đến sự gia tăng cung cấp máu đến xoang trán đang phát triển [1][5].

Các biến chứng nội sọ từ xoang có thể xảy ra bằng cách lan trực tiếp qua sự ăn mòn thành xương của xoang, tồn tại lổ, hoăc khuyết do chấn thương cũng như thổng qua dẫn lưu xoang tĩnh mạch tủy xương ít van [10]. Sự lan rộng của nhiễm trùng qua thành sau của xoang trán có thể dẫn đến hình thành áp xe ngoài màng cứng hoặc tụ mủ dưới màng cứng.

\section{CA LÂM SÀNG:}

Trường hợp 1: bệnh nhân nữ 62 tuổi vào viện vì đau đầu dữ dội vào ngày 15 tháng 12 năm 2017.

Bênh sử: 6 tuần trước bênh nhân đau răng bên phải, được chẩn đoán viêm xoang hàm phải/ Đái thào đường type II được điều trị tại Bệnh viện địa phương 1 tuần. Các triệu chứng tắng dần, lúc này bênh nhân đau đầu dữ dội, sụp mi mắt phải và mờ mắt phải và tiếp xúc chậm. Nên bệnh nhân được chuyển đến Bệnh viện Chợ Rẫy. Sau xét nghiệm và chụp $\mathrm{CT}$ Scan, chẩn đoán xác định là: Viêm xoang hàm phải biến chứng áp xe não/ đái tháo đường type 2 . Được điều trị nội 
khoa Được điều trị nội khoa với kháng sinh Meropenem + Vancomycin + Metronidazole + giảm đường huyết (Metformin) trong 2 tuần tại khoa Ngoại thần kinh, các triệu chứng cải thiện
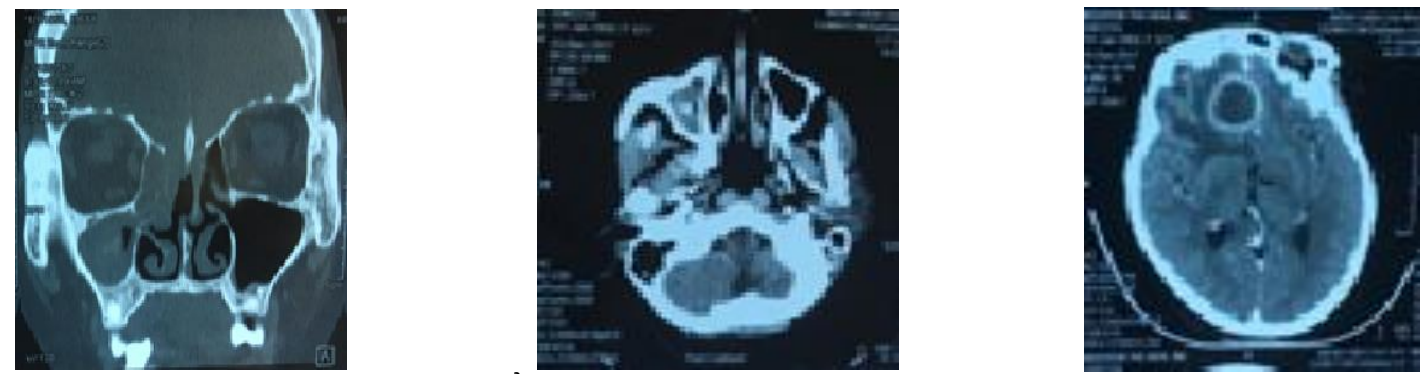

Hình 1: CT Scan (15/12/2017): tổn thương não thùy trán phải, kèm dày niêm mạc xoang sàng 2 bên, xoang bướm và xoang hàm phải, lan vào khoang ngoài nón hốc mắt phải. Nghĩ đến viêm đa xoang lan vào hốc mắt phải và lan vào nội sọ gây áp xe não trán phải.

Sau xuất viện 2 tuần. Bệnh nhân bị đau đầu dữ dội trở lại. Kèm theo là sụp mi mắt và mờ mắt bện phải, ngủ gà, İơ đễnh. Được chẩn đoán viêm xoang hàm phải do nấm, biển chứng áp xe não/ đái tháo đường type 2. Điều trị nội khoa với kháng sinh theo phát đồ phối hợp 3 kháng sinh.

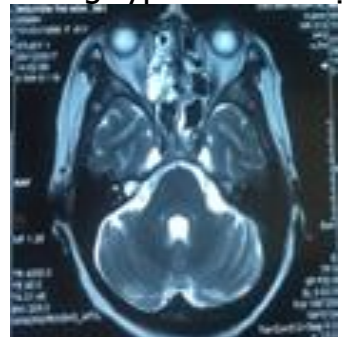

Hinh 2: MRI (01/01/2018): tổn thương choán chỗ nhu mô não trán phải \# $2 * 2,7 \mathrm{~cm}$, liên tục với tổn thương từ xoang sàng, xoang bướm bên phải, khoang ngoài nón phải nghỉ abscess. Dày niêm mạc, tụ dịch xoang hàm, xoang sàng xoang trán, xoang bướm 2 bên

Sau hội chẩn: Trên MRI ổ abscess liên tục với tổn thương từ xoang sàng, xoang bướm bên phải nên đường dẫn lưu abscess tốt nhất là qua nội soi mũi xoang. TMH và ngoại thần kinh quyết định dẫn lữu áp xe qua đường mũi và giải tình trạng viêm xoang hàm phải. bệnh nhân được mở xoang hàm bằng đường Caldwell luc + mở khe dưới lấy ra nhiều tổ chức nghi nấm, phẫu thuật nội soi mở rộng lỗ thông xoang hàm + nạo

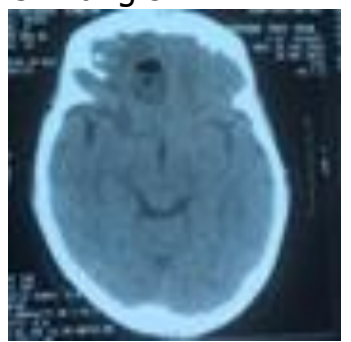

sàng trước sau + mở xoang trán + mở xoang bướm + cắt xương cuốn giữa và phần sau vách ngăn bị hoại tử, thấy ổ abscess não trán thông xuống phía trước xoang bướm. Tiến hành nong + súc rửa ổ abscess.

Sau phẫu thuật bệnh nhân cần tiếp tục sử dụng kháng sinh đường tĩnh mạch ít nhất 6 tuần.

Trường hợp 2: Vào ngày 8 tháng 3 năm 2021 có bệnh nhân nữ 37 tuổi vào viện vì đau đầu nhiều và tăng dần, kèm theo đau đầu là sụp mi mắt phải, hạn chề vận nhãn phí trong. Tiền sử: có chảy mũi, nghẹt mũi hắc hơi. Có điều trị tại địa phương nhưng không giảm. Được chuyển lển tuyến BV Chợ Rẩy. Hình ảnh CT scan chụp cản quang.

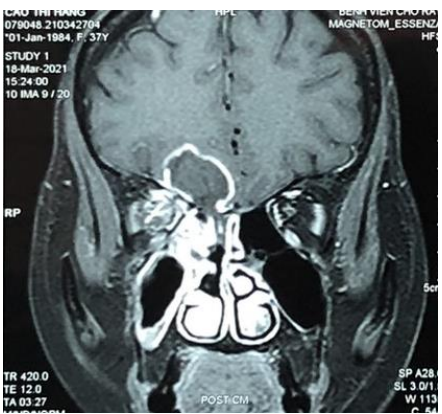

Hình 3: tổn thương xoang sàng phải lan vào đỉnh hốc mắt và khoang trong nón phải, lan vào
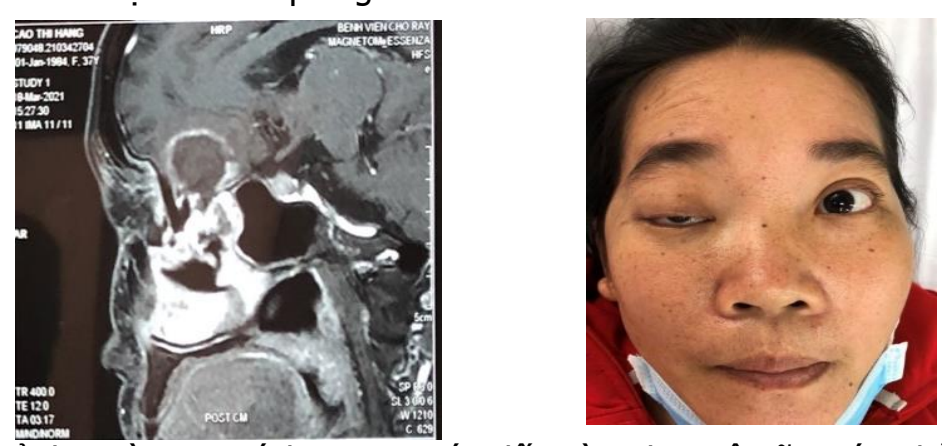

ngách xoang trán, lấn vào nhu mô não trán phải, kích thước \# 3cm, bắt thuốc mạnh quanh viền, 
có giới hạn.

Bệnh nhân được chẩn đoán là viêm xoang mạn biến chứng áp xe não. Được xử trí điều trị kháng sinh (Vancomycin + Ceftriaxone + Metronidazole) kết hợp với mổ nội soi xoang, mở khe giữa nạo sàng trước sau, xoang trán, và qua trần sàng trước dẫn lưu phần áp xe trên não, bơm rửa sạch. Sau 4 tuần điều trị, tình trạng bệnh ổn và xuất viện.

Trường hợp 3: Vào ngày 27 tháng 2 năm 2021 có bệnh nhân nam 47 tuổi, vào viện vì đau đầu nhiều, kèm theo đau đầu là sốt lạnh run, buồn nôn, sợ ánh sáng, cổ cứng, có dấu hiệu viêm màng não. Ngoài ra, còn có triệu chứng mũi xoang: chảy mũi xanh, hắc hơi, ngứa mũi và nghẹt mũi. Có tiền sử đang điêu trị đái tháo đường. Hình ảnh CT scan: viêm đa xoang, nấm xoang hàm phải, Hình ảnh MRI: có tổn thương áp xe thùy thái dương trái giảm đậm độ, có viền rõ bắt thuốc cản từ, phù nề mô não xung quanh tổn thương áp xe vùng thái dương.

Bệnh nhân được điều trị nội khoa kháng sinh (Meropenem + Metronidazole), kết hợp phẫu thuật mổ nội soi xoang, lây sách bệnh tích sàng hàm bướm trán và lấy sạch nấm xoang hàm phải. Được tiếp tục điều trị kháng sinh. Sau 5 tuần điều trị, tình trạng bệnh cải thiện nhiều và xuất viện.

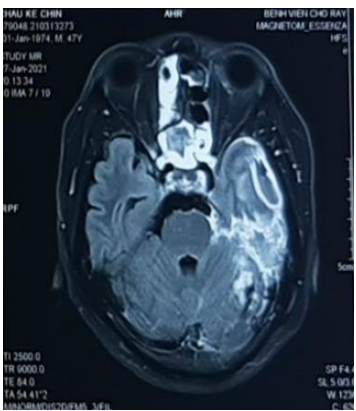

Viêm xoang sàng bướm phải + áp xe nã thùy thái dương trái

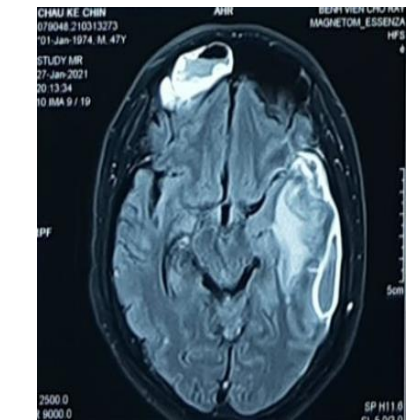

Viêm xoang trán phải + áp xe thùy thái dương trái

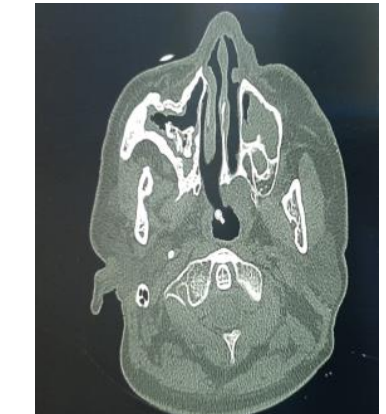

Viêm xoang hàm phải dạng nấm xoang hàm

Hình 4: tổn thương viêm xoang hàm sàng trán bướm bên phải, nấm xoang hàm phải biến chứng áp xe não vùng thái dương trái.

\section{BÀN LUÂ̂N}

3.1. Lâm sàng: Bênh nhân viêm xoang liên quan đến biến chứng nội sọ hầu hết biểu hiện với các dấu hiệu tăng áp lực nội sọ hơn là các dấu hiệu của viêm xoang [9]. Ban đẩu khám dấu hiệu thần kinh có thể bình thường và các dấu hiệu viêm gia tăng chậm, đặc biệt nếu bệnh nhân đã sử dụng kháng sinh. Hầu hết các bệnh nhân đều nằm khoa ngoại thần kinh, vì dấu hiệu viêm xoang biểu hiện không rõ hay lu mờ so với triệu chứng tăng áp lực nội sọ. Bệnh nhân bị abscess não thùy trán hay gặp các triệu chứng: đau đầu, ngủ gà, lơ đễnh, thay đổi tính tình, liệt nửa người, loạn ngôn.

Bệnh nhân trường hợp 1 đã có 1 số triệu chứng như đau đầu, ngư gà, lơ đễnh, còn các triệu chứng sụp mí phải và giảm thị lực có thể do sự chèn ép của khối abscess vào cuống não. Diễn tiến của abscess não trên bệnh nhần này không rầm rộ, điều này phù hợp với diễn tiến của abscess não do biến chứng viêm xoang thường diễn tiến âm thầm (không có hội chứng nhiễm trùng rõ). Tuy nhiên, bệnh diễn bán cấp (từ khi khởi phát đến khi phẫu thuật là 8 tuần).
Trên MRI sọ não khối choán chỗ có vỏ trơn láng, bờ viền mỏng, tăng tín hiêu ít so với dịch não tủy trên $\mathrm{T} 1$ giúp ta nghĩ nhiều tổn thương này là abscess hơn là khối u.

Về giai đoạn của abscess não: abscess có 4 giai đoạn: giai đoạn viêm não sớm (ngày 1-3), giai đoạn viêm não muộn (ngày 4-9), giai đoạn tạo vỏ abscess sớm (ngày 10-13), và giai đoạn tạo vỏ abscess muộn (ngày 14 trở đi) [8]. Như vậy bệnh nhân này bị abscess não giai đoạn tạo vỏ abscess muộn.

3.2. Hình ảnh học: Khi nghi ngờ tụ mủ nội sọ, CT sacn xoang và MRI não được khuyến cáo thực hiện để đánh giá [6]. CT scan có giá trị trong hầu hết các trường hợp, đặc biệt cho chuẩn bị phẫu thuật thần kinh khẩn cấp. CT scan có giá trị trong các bệnh lý xương ở trong sọ, xương và xoang vùng mặt tốt hơn MRI. Mặt khác, $\mathrm{CT}$ scan có hình ảnh rõ ràng và độ nhạy thấp hơn. Hình ảnh CT scan/ MRI chỉ định áp xe ngoài màng cứng trong đó tụ mủ dưới màng cứng lan rộng. MRI đánh giá tốt các thương tổn áp xe trong não và các mô não xung quanh. Do đó, khi chẩn đoán viêm xoang biến chứng não cần chụp cả CT scan và MRI. 
3.3. Tác nhân vi khuẩn trong viêm xoang biến chứng áp xe não: Bệnh nhân bị ĐTÐ type 2 là 1 yếu tố thuận lợi của abscess não. Trên MRI ổ abscess liên tục với tổn thương từ xoang sàng, xoang bướm bên phải nên có thể do viêm nhiễm từ xoang lan lên trực tiếp lên mô não tại vị trí sàn sọ trước, gây abscess não. Tuy nhiên, ở trường hợp 3 thì viêm hàm, sàng, trán bướm bên phải nhưng áp xe não bên thùy thái dương phải, như vậy khả năng đường lan truyền có thể qua đường máu vào não.

Trong quá trình dẫn lưu mủ trong ổ áp xe não, được đem đi cây tìm vi khuẩn, tìm lao, tìm nấm để làm rõ thêm cho chẩn đoán và phục vụ cho điều trị (trên bệnh nhân ĐTĐ dễ bị nhiễm trùng cơ hội). Trong abscess não thì streptococcus là nguyên nhân gây bệnh hay gặp nhất $(33-50 \%)$, và trong abscess não do biến chứng viêm xoang hay gặp vi khuẩn Strept. Melleri và Strept. Angiosus [8].

Hầu hết bệnh nhân hiện diện với Streptococcus pneumonia, intermedius hoặc anginosus, vẫn có trường hợp Haemophilus influenza [4]. Bên cạnh đó, bệnh nhân có xuất hiện loài Prevotella và Candida được cây từ nhiễm trùng nội sọ do xoang có thể do đơn bào hoặc đa bào với loài Streptococcal và Staphylococcal. Brook [2] đã chứng minh có hiện diện vi khuẩn yếm khí như Prevotella và Peptostreptococcus được cấy ở viêm xoang trán mạn, Haemophilus influanzae và Streptococcus penumoniae thường gặp trong viêm xoang trán cấp.

3.4. Điêu trị: Điêu trị kháng sinh trên bệnh nhân này cần sử dụng kháng sinh phổ rộng, liều cao và thấm tốt qua màng não. Đâu tiên cần sử dụng kháng sinh đường tĩnh mạch trong 2 tuần sau đó sẽ sử dụng kháng sinh đường uống trong 4 tuần tiếp theo [8]. Theo Joe M. Das bệnh nhân bị abscess não do biến chứng viêm xoang nên phối hợp kháng sinh gồm: metronidazole + cephalosporin thế hệ 3 + vancomycin.

Áp xe não và tụ dịch ngoài màng cứng nhỏ với kích thước nhỏ hơon $2 \mathrm{~cm}$ có thể điều trị không phẫu thuật. Mặc dù, $1 / 4$ nhiếm trùng nội sọ gây ra từ xoang và từ tai ở trẻ em không cần phải phẫu thuật [10]. Chỉ định can thiệp phẫu thuật khi muốn cải thiện các triệu chứng khối trong nội sọ hoặc muốn chẩn đoán tác nhân vi sinh. Trên $65 \%$ mẫu mủ trong sọ cây dương tính [5],[6]. Các bệnh nhân trong nhóm nghiên cứu sử dụng kháng sinh khác nhau tùy thuộc vào hướng dẫn tác nhân nhiễm khuẩn tại chổ và chẩn đoán ban đầu. Nó thường phổ biến cho bệnh nhân sử dụng liệu pháp kháng sinh khi áp xe ngoài màng cứng/ dưới màng xương tiến triển [5]. Áp xe tiếp tục tiến triển do chẩn đoán sai hoặc thiếu điều kiện điều trị tại địa phương. Nếu lẩm sàng nghi ngờ bệnh nền viêm xoang trán hoặc liên quan đến biến chứng, kháng sinh nên không nên trì hoản chờ kết quả cấy vi khuẩn. Chưa có chứng cứ về thử nghiêm điều trị, cephalosporin thế hệ mới (ceftriaxone) kèm với kháng sinh yếm khí (metronidazole) đã được khuyến cáo đủ điều kiện phối hợp[6]. Khi Staphylococcus aureus kháng methicillin được phân lập, vancomycin nên được bổ sung. Kháng sinh nên dùng 4 -8tuần.

Chụp MRI theo dõi hàng tuần cho đến khi khối abscess biến mất. Nếu tình trạng bệnh nhân sau mổ 2 tuần mà khối abscess lớn hơn hay sau 3-4 tuần mà kích thước khối abscess không thay đổi thì cần phải phẩu thuật nội soi mũi xoang dẫn lưu mủ lần 2 hoặc mở sọ não bóc trọn ổ áp xe. Trong 3 trường hợp trong nhóm nghiên cứu, 2 trường hợp phải dẫn ổ mủ trong não qua đường xoang sàng kết hợp với phẫu thuật nội soi xoang. Trường hợp viêm xoang vùng thái dương trái thì chúng tôi điều trị nội khoa (kháng sinh phối hợp) với phẫu thuật nội soi lấy tổn thương viêm và mô nâm xoang hàm phải, không cần dẫn lưu ổ mủ trong não. Kết quả 3 trường hợp phục hồi tốt.

Vai trò của corticosteroids vẫn còn tranh luận. Corticosteroids nên hạn chế ngoại trừ bệnh nhân biểu hiện các dấu hiệu của viêm màng não hoặc hình ảnh CT scan/ MRI biểu hiện rõ nhiễm trùng ngoài màng cứng hoặc dưới màng cứng - giảm khối ảnh hưởng với nguy cư của thoát vị não cấp. Corticosteroids hiệu quả giảm phù não và ngăn cản quá trình hình thành vỏ bao. Chúng cũng làm giảm sự thâm nhập của kháng sinh vào ổ áp xe và tăng hoại tử nguy cơ vỡ não thất [2],[8] đây là lý do tại sao corticosteroid không được khuyến cho điều trị áp xe nhu mô não. Chưa có thử nghiệm lâm sàng kiểm soát để hướng dẫn liều và thới gian điều trị, corticosteroids nói chung nên chỉ sử dụng trong thời gian ngắn.

Những bệnh nhân với biến chứng áp xe nội sọ bắt nguồn từ xoang cần phẫu thuật xoang. Chữa có sự thống nhất trong hướng dẫn cho loại phẫu thuật và thời gian phẫu thuật. Mặc dù, điều trị đa chuyên nghành là cần thiết bao gồm tai mũi hơng và ngoại thần kinh. Sự phối có này cỏ thể diễn ra đồng thời hoặc khác thời điểm. điều này có thể đã được tranh luận, phẫu thuật ngoại thần kinh sớm có thể làm giảm thời gian nằm viện, giảm cần thiết cho kéo dài phẫu thuật, và 
hoặc quan trọng hơn, cải thiện tiên lượng cho bệnh nhân. Thống nhất với các nghiên cứu trước đầy, chúng tôi ủng hộ dẫn lưu cả hai nguồn nhiếm khuẩn và mủ nội sọ và kết hợp kháng sinh liệu pháp sẽ giảm tình trạng bệnh, tỷ lệ tử vong và tỷ lệ tái phát [1].

Nếu xương xoang trán bị hoại tử dẫn đến viêm xương, loại bỏ vùng nhiễm trùng bao gồm áp xe cốt mạc, xương viêm, áp xe ngoài màng cứng, và mô hat được khuyến nghị. Hơn nữa, cố gắng cắt và kiểm tra thành sau của xoang trán [3]. Khi loại bỏ mô hạt viêm từ màng cứng, chú ý tránh là̀m thủng và đưa nhiễm trùng vào khoang dưới màng cứng. Tỷ lệ tử vong khoảng $30 \%$ ở những bệnh nhân tụ mủ dưới màng cứng, trong khi đó áp xe ngoài màng cứng tách biệt có thể được điều trị không có tử vong [7]. Mắt khác, mở sọ của xương trán có tính thẩm mỹ và ngày nay được xem không cần thiết khi xương trán bị mòn có khả năng lành $6-8$ tuần dùng liệu pháp kháng sinh.

\section{KẾT LUÂN:}

Viêm xoang biến chứng áp xe não ngày nay ít gặp do sự phát triển và sử dụng kháng sinh rộng rãi. Tuy nhiên, khi xảy ra thì nguy hiếm đến tính mạng. Cần chẩn đoán sớm và điêu trị thích hợp kháng sinh theo kinh nghiệm trước, thâm chí kết hợp với phẫu thuật nội qua qua mũi hoặc mở não để dẫn lưu ổ mủ trong não là phương pháp triệt để giải quyết áp xe não do xoang , giúp bệnh nhân hồi phục sớm, giảm tỷ lệ biến chứng.
TÀI LIẸU THAM KHẢO

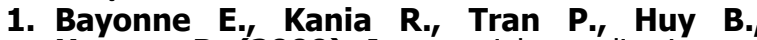
Herman P. (2009), Intracranial complications of rhinosinusitis. A review, typical imaging data and algorithm of management. Rhinology, 47(1), 59-65.

2. Brook I. (2002), Bacteriology of acute and chronic frontal sinusitis. Arch Otolaryngol Head Neck Surg, 128 (5), 583-5.

3. Clayman G. L., Adams G. L., Paugh D. R., Koopmann C. F., Jr. (1991), Intracranial complications of paranasal sinusitis: a combined institutional review. Laryngoscope, 101 (3), 234-9.

4. Germiller J. A., Monin D. L., Sparano A. M. Tom L. W. (2006), Intracranial complications of sinusitis in children and adolescents and their outcomes. Arch Otolaryngol Head Neck Surg, 132 (9), 969-76.

5. Hicks C. W., Weber J. G., Reid J. R., Moodley M. (2011), Identifying and managing intracranial complications of sinusitis in children: a retrospective series. Pediatr Infect Dis J, 30 (3), 222-6.

6. Kombogiorgas D., Seth R., Athwal R., Modha J., Singh J. (2007), Suppurative intracranial complications of sinusitis in adolescence. Single institute experience and review of literature. $\mathrm{Br}$ J Neurosurg, 21 (6), 603-9.

7. Legrand M., Roujeau T., Meyer P., Carli P., Orliaguet G., Blanot S. (2009), Paediatric intracranial empyema: differences according to age. Eur J Pediatr, 168 (10), 1235-41.

8. Muzumdar D., Jhawar S., Goel A. (2011), Brain abscess: an overview. Int J Surg, 9 (2), 136-44.

9. Nicoli T. K., Oinas M., Niemelä́ M., Mäkitie A A., Atula T. (2016), Intracranial Suppurative Complications of Sinusitis. Scand J Surg, 105 (4) 254-262.

10. Piatt J. H., Jr. (2011), Intracranial suppuration complicating sinusitis among children: an epidemiological and clinical study. J Neurosurg Pediatr, 7 (6), 567-74.

\section{ĐIỀU TRI DUY TRÌ BẰNG OLAPARIB Ở BÊ̂NH NHÂN UNG THƯ BUỒNG TRỨNG TIẾN XA MỚI CHẨN ĐOÁN}

Phạm Trí Hiếu ${ }^{1}$, Nguyễn Văn Thắng ${ }^{2}$, Trần Thị Thanh Huyền ${ }^{3}$

\section{TÓM TẮT}

Đặt vấn đề: Hầu hết phụ nữ ung thư buồng trứng (UTBT) giai đoạn tiến xa mới chẩn đoán, sau khi điêu trị chuân bằng phẫu thuật và hóa trị liệu có chứa Platinum sẽ tái phát trong 3 năm đầu. Olaparib là thuốc ức chế enzym poly (adenosine diphosphateribose) polymerase, có hiệu quả tốt trong điều trị ung

${ }^{1}$ Bênh viện Phụ sản Trung Uơng

${ }^{2}$ Bệnh viện Phù sản Trung Ương

${ }^{3}$ Trung tâm cống nghê cao - Bệnh viên Vinmec

Chịu trách nhiệm chính: Phạm Trí Hiểu

Email: Thongke8@gmail.com

Ngày nhận bài: 16.8.2021

Ngày phản biên khoa hoc: 18.10.2021

Ngày duyệt bài: 27.10.2021 thư buồng trứng tái phát, nhưng lơi ích của Olaparib trong điều trị duy trì đối với các trường hợp mới được chẩn đoán chưa được chứng minh. Phương pháp: Thử nghiệm lâm sàng pha 3, đa trung tâm, ngâu nhiên, mù đôi, nhằm đánh giá hiêu quả của Ólaparib như một liệu pháp duy trì ở những bệnh nhân mới được chẩn đoán ung thư buồng trứng giai đoan III IV theo FIGO; gôm các thể: ung thư biểu mồ thanh dich hoăc ung thư dang nội mac tử cung, đô ác tính cao, ung thư phúc mạc nguyên phát, ung thư vòi tử cung (hoăc các dang kết hợp), với đột biến ở gen BRCA1, BRCA2 hoặc cả hai; đã có đáp ứng lâm sàng hoàn toàn hoăc một phân sau khi hóa trị liệu bằng hóa trị có chứa Platinum. Các bênh nhân được chỉ định ngấu nhiên, theo tỷ lệ $2: 1$, được uống Olaparib (300mg hai lần mỗi ngày) hoặc giả dược. Tiêu chí 